\title{
Expanding nurse practice in COPD: is it key to providing high quality, effective and safe patient care?
}

\author{
*Monica J Fletcher ${ }^{1}$, Birthe H Dahl' \\ ${ }^{1}$ Education for Health, Warwick, UK \\ ${ }^{2}$ Center of Public Health and Quality Improvement, Århus, Denmark
}

Originally received 19th December 2012; resubmitted 19th February 2013; revised 11th March 2013; further revision 20th March 2013; accepted 21st March 2013; online 10th May 2013

\begin{abstract}
The prevalence of chronic obstructive pulmonary disease (COPD), a common and preventable chronic disease, is on the increase, and so are the financial and social burdens associated with it. The management of COPD is particularly challenging, as patients have complex health and social needs requiring life-long monitoring and treatment. In order to address these issues and reduce the burden imposed by COPD, the development of innovative disease management models is vital. Nurses are in a key position to assume a leading role in the management of COPD since they frequently represent the first point of contact for patients and are involved in all stages of care. Although evidence is still limited, an increasing number of studies have suggested that nurse-led consultations and interventions for the management of COPD have the potential to impact positively on the health and quality of life of patients. The role of nurses in the management of COPD around the world could be significantly expanded and strengthened. Providing adequate educational opportunities and support to nurses, as well as addressing funding issues and system barriers and recognising the importance of the expanding roles of nurses, is vital to the well-being of patients with long-term medical conditions such as COPD and to society as a whole, in order to reduce the burden of this disease.

(C) 2013 Primary Care Respiratory Society UK. All rights reserved.

MJ Fletcher and BH Dahl. Prim Care Respir J 2013; 22(2): 230-233

http://dx.doi.org/10.4104/pcrj.2013.00044
\end{abstract}

Keywords nurses, COPD, education and training, impact or outcomes

\section{Introduction}

Chronic obstructive pulmonary disease (COPD) is a common chronic condition associated with a rapidly increasing physical, social, and economic burden in terms of both direct healthcare costs including hospitalisations and medication and indirect costs (productivity loss, work absenteeism, premature retirement). ${ }^{1}$ It is estimated that approximately 210 million people worldwide have COPD, ${ }^{2}$ and its incidence is believed to be rising. ${ }^{3}$ Mortality predictions suggest that COPD will become the third leading cause of death in 2020 and the fourth leading cause of death in $2030 .{ }^{4}$ There is therefore an urgent need to develop innovative COPD management models. In this context, nurses are uniquely positioned to make a substantial contribution as they are often the first point of contact for patients and are actively engaged throughout the disease management process, frequently providing palliative care.

In this discussion paper we explore the role of nurses in the management of COPD and highlight some of the barriers which are currently preventing nurses from expanding and strengthening their role. We also suggest some possible strategies to help nurses overcome these obstacles.

\section{COPD and nursing: from prevention to palliation}

The nursing role in COPD - and essentially in all chronic diseases - is becoming increasingly important and is characterised by continuity of care. Nurses are involved in the management of COPD at all stages, from prevention to provision of end-of-life care within a variety of settings, both in the community (including patients' own homes and family practice) and hospitals. Nurses often play a key role in new care models based on different types of telemedicine support. 5,6 Nurse-led consultations and disease management interventions are important interventions which enable nurses to provide, complement, or extend the care delivered by doctors. Nurse-led consultations carried out by experienced nurses frequently include tasks that traditionally belong to physicians, such as physical examination of patients, diagnosis and, in countries such as the UK,

\footnotetext{
* Corresponding author: Ms M onica J Fletcher, Education for Health, The Athenaeum, 10 Church Street, Warwick CV34 4AB, UK.

Tel: +44 (0)1926 836841 Fax: +44 (0)1926 493224 E-mail: m.fletcher@educationforhealth.org
} 
prescription of medicines. Nurse-led management interventions are aimed at helping patients cope with their condition and improve their quality of life. They include patient education, guided selfmanagement, smoking cessation, and pulmonary rehabilitation programmes.

\section{Nurse-led consultations}

Over the last decade there has been an expansion in the role of nurses in the management of respiratory diseases. A pilot study investigating the role of nurses providing respiratory care revealed that nurses were involved in the delivery of the majority (68\%) of long-term respiratory disease management, primarily for asthma and COPD. ${ }^{7}$ The results of a survey conducted in 2006 describing nurseled COPD clinics in general practice in the UK demonstrated that a large percentage of nurses in an advanced role recommended both pharmacological and non-pharmacological interventions, and autonomously provided follow-up care and confirmed diagnosis via spirometry. ${ }^{8}$

Studies evaluating the impact of nurse-led care in the management of various chronic diseases revealed that nurses and doctors generated similar health outcomes for patients ${ }^{9-12}$ Similarly, studies in both acute and chronic care settings have shown that care provided by nurses is as safe as that provided by doctors. ${ }^{10,11,13}$ In addition, the systematic review by Horrocks et al. reported higher patient satisfaction with nurse-delivered care compared with care provided by doctors. ${ }^{13}$ In particular, patients were given significantly more advice about self-management and self-medication during nurse consultations. More recently, a study involving Danish nurses delivering consultations to patients after cancer surgery identified one of the reasons for increased patient satisfaction in the continuity of care which is at the core of the nursing profession. ${ }^{14}$

\section{Nurse-led management interventions}

Traditionally, nursing care has been characterised by a holistic approach towards disease management. In COPD, nurses have been involved in delivering non-pharmacological interventions aimed at reducing symptoms and improving the quality of life of patients such as smoking cessation, increased physical activity, and pulmonary rehabilitation. ${ }^{15}$ The increase in the prevalence of chronic diseases has led to the development of more comprehensive and multimodal approaches, combining some or all of these areas of traditional nursing care with patient education and mentoring interventions aimed at improving patient self-efficacy and enhancing long-term health status.

Smoking cessation interventions have been shown to be effective when used alone or in conjunction with other interventions. ${ }^{16-18}$ Evidence of the effectiveness of more comprehensive nurse-led multidisciplinary programmes is also starting to emerge. A one-year longitudinal study in 103 COPD patients investigating the effect of a nurse-led programme of pulmonary rehabilitation argues in favour of a positive impact of nurses' interventions in the management of COPD. ${ }^{19}$ Patients in the intervention group experienced a significantly greater improvement in exacerbation frequency compared with the control group; no significant differences in functional capacity or quality of life were seen. ${ }^{19} \mathrm{~A}$ randomised controlled trial in 122 patients also evaluated the effect of a nurse-led care programme incorporating initial pulmonary rehabilitation and self-management education, provision of a written personalised COPD action plan, and follow-up care by monthly telephone interviews in patients admitted to hospital for COPD exacerbations. ${ }^{20}$ The study indicated that these interventions were associated with a reduced need for unscheduled primary care consultations and a reduction in deaths due to COPD, but did not affect the hospital readmission rate.

A recently published 12 -month controlled clinical trial in which nurses acted as mentors to 106 COPD patients to increase selfmanagement behaviours has shown that this approach significantly improved health-related quality of life (HRQoL), physical functioning, and increased time to death or readmission to hospital. ${ }^{21}$ In addition, it has been suggested that comprehensive nursing practice addressing the needs of patients with COPD could be beneficial for patients and their families. ${ }^{22}$ As COPD has a profound impact on both patients and their families, is complex and characterised by fluctuating symptoms, the education of families is extremely important for the effective management of this condition. The study by Ingadottir et al. involved 50 patients with COPD and was notable in that it was based on the establishment of family involvement. ${ }^{22}$ In this study, nurses assisted not only patients but also their families in learning to assess and take appropriate measures in relation to symptoms, establishing a close collaboration with family members and other healthcare professionals. In addition, nurses addressed specific health-related issues according to the needs of the individual patient. All the main variables measured - such as disease-specific HRQoL, number of hospital admissions, nutritional status, and anxiety and depression - improved significantly; measures of HRQOL also reached a clinically significant threshold.

Despite these positive results, two reviews of clinical trials aimed at assessing the effect of various interventions (self-management education programmes, telephone follow-up, physical activity) that were led, coordinated, or delivered by nurses failed to show significant patient benefit. ${ }^{23,24}$ More research including larger numbers of patients is needed to establish fully the effectiveness of nurse-led interventions and which model achieves the best outcomes.

Nurses have consistently shown a positive contribution in delivering the hospital-at-home and early discharge schemes for COPD. ${ }^{25,26}$ Under these schemes, patients with acute exacerbations are cared for at home by a specialist respiratory nurse with the support of a hospital-based multidisciplinary team. These interventions are particularly important considering that COPD exacerbations are one of the most common causes of hospital admission and are responsible for an increased demand of hospital beds. Two systematic reviews evaluating the efficacy of hospital-athome care in patients with acute COPD exacerbations have shown that treatment of these patients at home resulted in a numerically reduced or unchanged mortality rate when compared with hospital inpatient care. ${ }^{25,26}$ This suggests that patients with acute exacerbations can be safely and successfully treated at home with support from respiratory nurses. In addition, discharge support and follow-up interventions, based on visits by nurses aimed at 
reinforcing education and promoting compliance with therapy, have been shown to be useful in shortening hospital stay. ${ }^{27}$

\section{Expanding nursing practice: what are the challenges?}

The increasing social and financial burden of COPD has driven the interest in clinical service innovations with regard to the management of patients. Nurses have considerably expanded their practice in recent years, particularly outside hospital settings. However, we believe that obstacles still need to be overcome in order to allow nurses to further strengthen their role and thereby contribute to the delivery of high-quality cost-effective care. The results of a nationwide survey which characterised the role of primary care respiratory nurses in the UK revealed that $<20 \%$ of nurses performing spirometry to diagnose COPD had undertaken formal training. ${ }^{8}$ Furthermore, $45 \%$ of nurses working in an advanced role who did not have accredited COPD training also did not have routine access to a doctor. This is of particular concern as UK practice nurses providing advanced-level care are routinely recommending or prescribing drug treatments.

Although research on the role of nurses in COPD management is still in its infancy, the evidence seems to suggest that this lack of training may affect the quality of care provided to patients and, in addition, have a detrimental effect on patient safety. A study by Bunker et al. investigating the effectiveness, feasibility, and acceptability of using practice nurses to diagnose COPD indicated that, although nurses were performing spirometry and interpreting results, there were a significant number of inaccurate diagnoses. ${ }^{28}$ The authors suggested that these inaccuracies may be reduced by longer and more intensive training. ${ }^{28}$ More recently, a study evaluating the efficacy in reducing the risk of hospitalisation of comprehensive care management programmes (30\% of which were delivered by nurses across six different sites) has raised concerns over the safety of this type of intervention as increased mortality was observed in the treatment group..$^{29}$ The intervention consisted of four weeks of 90-min education sessions including an action plan to identify and treat COPD exacerbations and scheduled telephone calls from a case manager. Although the cause of the excessive mortality in this study is unknown, lack of appropriate training of healthcare professionals or patients involved in the programme in properly recognising symptom severity and starting appropriate treatment may be a factor. The importance of training is further supported by a study in other chronic conditions in which community and specialist nurses involved in delivering selfmanagement programmes have been shown to be limited in facilitating self-management in patients, mainly due to lack of professional confidence. ${ }^{30}$ The study suggests that this problem could be overcome by providing further training and education to community nurses. In addition, a qualitative study exploring the involvement of practice nurses in the facilitation of selfmanagement for long-term conditions in the UK concluded that additional training and support was needed for effective delivery of self-management support, specifically in cognitive behaviour principles and practice. ${ }^{31}$
However, it is starting to emerge that lack of training is only one of the issues that nurses are facing. A study investigating the potential for general practice nurses to act as health mentors to assist COPD patients implementing self-management and behavioural changes has generated interesting results. In the study, a high proportion of general practice nurses $(74 \%)$ were unable to train as mentors due to either lack of financial support or workload pressure, suggesting that significant system barriers need to be addressed through new funding models and organisational changes. ${ }^{32}$ This will only be possible if the role of nurses is formally recognised and institutionalised, which will also allow the definition of specific education requirements and appropriate remuneration. We believe that addressing these issues could result in nurses becoming more involved in prevention, care, and management of individuals with chronic diseases in general, and COPD in particular, and playing a more active role in new and more effective care pathways and interventions.

\section{Conclusions}

Nurses represent an appropriate resource to deliver care and support to individuals with COPD throughout the entire course of the disease. Even though more research is needed to establish the effectiveness of nurse-led interventions and consultations, there is some growing evidence to demonstrate the benefits provided by these interventions, particularly in relation to the hospital-at-home and early discharge schemes, smoking cessation, and pulmonary rehabilitation programmes as well as interventions aimed at improving self-management behaviour. Studies have also shown that nurses are able to deliver care that is as effective as that provided by doctors. However, a paucity of standardised competencies and specified training requirements - coupled with a lack of clinical supervision, appropriate funding, and workload pressures among nurses delivering COPD care - highlight specific areas for improvement. Nurses need to strengthen their role to plan and deliver more strategies to improve the quality of life of patients with COPD and reduce the burden of this disease in the future. In doing so, nurses cannot assume an increased responsibility in isolation. More coordinated efforts and better mentorship and support from colleagues, along with a formal recognition of their new role, is needed to allow nurses to provide high-quality, safe, and cost-effective care and, in that way, to optimise the use of limited healthcare resources worldwide.

\section{Handling editor Maureen George}

Acknowledgements Roberta Sottocornola (Circle Science, Tytherington, Cheshire, UK) assisted in preparing the manuscript that was critically reviewed and revised by the authors, but did not meet the ICMJE criteria for authorship (www.icmje.org/) She did not provide any input on the intellectual content of the manuscript.

Conflicts of interest MF is Chief Executive and therefore a paid employee of Education for Health which is a not-for-profit charity whose aim is to improve the care of people living with long-term conditions through the education and training of healthcare professionals. BD has no competing interests.

Contributorship All authors were involved in the concept and design of this article. All authors revised the article critically for important intellectual content and gave their final approval of the version to be published. 
Funding Writing support was funded by Novartis Pharma AG. The authors did not receive any payment for producing this paper.

\section{References}

1. Fletcher MJ, Upton J, Taylor-Fishwick J, et al. COPD uncovered: an international survey on the impact of chronic obstructive pulmonary disease (COPD) on a working age population. BMC Public Health 2011;11:612. http://dx.doi.org/10.1186/1471-2458-11-612

2. World Health Organization. The Global Burden of Disease 2004 Update. www.who.int/healthinfo/global_burden_disease/2004_report_update/en/index.html (accessed 25 February 2013)

3. Mannino DM, Buist AS. Global burden of COPD: risk factors, prevalence, and future trends. Lancet 2007;370:765-73. http://dx.doi.org/10.1016/S0140-6736(07)61380-4

4. Mathers $C D$, Loncar $D$. Projections of global mortality and burden of disease from 2002 to 2030. PLoS Med 2006;3:e442. http://dx.doi.org/10.1371/journal.pmed.0030442

5. de Toledo P, Jimenez S, Del Pozo F, Roca J, Alonso A, Hernandez C. Telemedicine experience for chronic care in COPD. IEEE Trans Inf Technol Biomed 2006;10:567-73. http://dx.doi.org/10.1109/TITB.2005.863877

6. Sorknaes AD, Madsen H, Hallas J, Jest P, Hansen-Nord M. Nurse tele-consultations with discharged COPD patients reduce early readmissions: an interventional study. Clin Respir J 2011;5:26-34. http://dx.doi.org/10.1111/j.1752-699X.2010.00187.x

7. Blake $D$, Roberts $N$ J, Partridge MR. How much of a primary care nurse's time is spent on those with respiratory disease? A pilot study. Prim Care Respir J 2007;16:319-20. http://dx.doi.org/10.3132/pcri.2007.00061

8. Upton J, Madoc-Sutton H, Sheikh A, Frank TL, Walker S, Fletcher M. National survey on the roles and training of primary care respiratory nurses in the UK in 2006: are we making progress? Prim Care Respir J 2007;16:284-90. http://dx.doi.org/10.3132/pcrj.2007.00068

9. Lowery J, Hopp F, Subramanian U, et al. Evaluation of a nurse practitioner disease management model for chronic heart failure: a multi-site implementation study. Congest Heart Fail 2012;18:64-71. http://dx.doi.org/10.1111/j.1751-7133.2011.00228.x

10. Moher M, Yudkin $P$, Wright $L$, et al. Cluster randomised controlled trial to compare three methods of promoting secondary prevention of coronary heart disease in primary care. BMJ 2001;322:1338. http://dx.doi.org/10.1136/bmj.322.7298.1338

11. Sharples LD, Edmunds J, Bilton D, et al. A randomised controlled crossover trial of nurse practitioner versus doctor led outpatient care in a bronchiectasis clinic. Thorax 2002;57:661-6. http://dx.doi.org/10.1136/thorax.57.8.661

12. van Zuilen $A D$, Blankestijn PJ, van $B M$, et al. Nurse practitioners improve quality of care in chronic kidney disease: two-year results of a randomised study. Neth J Med 2011;69:517-26.

13. Horrocks S, Anderson E, Salisbury C. Systematic review of whether nurse practitioners working in primary care can provide equivalent care to doctors. BMJ 2002;324:819-23. http://dx.doi.org/10.1136/bmj.324.7341.819

14. Piil K, Kolbaek R, Ottmann G, Rasmussen B. The impact of the expanded nursing practice on professional identify in Denmark. Clin Nurse Spec 2012;26:329-35. http://dx.doi.org/10.1097/NUR.0b013e31826e3f43

15. Global Initiative for Chronic Obstructive Lung Disease (GOLD). Global strategy for the diagnosis, managment and prevention of COPD. www.goldcopd.org/ (accessed 18 Dec 2012).

16. Dejong SR, Veltman RH. The effectiveness of a CNS-led community-based COPD screening and intervention program. Clin Nurse Spec 2004;18:72-9. http://dx.doi.org/10.1097/00002800-200403000-00012

17. Efraimsson EO, Nyberg A, Aberg-Lennmalm E. COPD care and management at nurse-led care COPD clinics in swedish primary health care: a literature review. Abstract presented at IPCRG 2012. Prim Care Respir J 2012;21:Abstract 233.

18. Sidorov J, Christianson M, Girolami S, Wydra C. A successful tobacco cessation program led by primary care nurses in a managed care setting. Am J Manag Care 1997;3:207-14

19. Zakrisson AB, Engfeldt P, Hagglund D, et al. Nurse-led multidisciplinary programme for patients with COPD in primary health care: a controlled trial. Prim Care Respir J 2011;20:427-33. http://dx.doi.org/10.4104/pcri.2011.00060

20. Sridhar M, Taylor R, Dawson S, Roberts NJ, Partridge MR. A nurse led intermediate care package in patients who have been hospitalised with an acute exacerbation of chronic obstructive pulmonary disease. Thorax 2008;63:194-200. http://dx.doi.org/10.1136/thx.2007.077578

21. Wood-Baker R, Reid D, Robinson A, Walters EH. Clinical trial of community nurse mentoring to improve self-management in patients with chronic obstructive pulmonary disease. Int J Chron Obstruct Pulmon Dis 2012;7:407-13. http://dx.doi.org/10.2147/COPD.S32220

22. Ingadottir TS, Jonsdottir H. Partnership-based nursing practice for people with chronic obstructive pulmonary disease and their families: influences on healthrelated quality of life and hospital admissions. J Clin Nurs 2010;19:2795-805. http://dx.doi.org/10.1111/j.1365-2702.2010.03303.x

23. Jonsdottir $\mathrm{H}$. Nursing care in the chronic phase of COPD: a call for innovative disciplinary research. J Clin Nurs 2008;17:272-90. http://dx.doi.org/10.1111/j.1365-2702.2007.02271.x

24. Taylor S), Candy B, Bryar RM, et al. Effectiveness of innovations in nurse led chronic disease management for patients with chronic obstructive pulmonary disease: systematic review of evidence. BMJ 2005;331:485. http://dx.doi.org/10.1136/bmj.38512.664167.8F

25. Jeppesen E, Brurberg KG, Vist GE, et al. Hospital at home for acute exacerbations of chronic obstructive pulmonary disease. Cochrane Database Syst Rev 2012; (5):CD003573.

26. Ram FS, Wedzicha JA, Wright J, Greenstone M. Hospital at home for patients with acute exacerbations of chronic obstructive pulmonary disease: systematic review of evidence. BMJ 2004;329:315. http://dx.doi.org/10.1136/bmj.38159.650347.55

27. Escarrabill J. Discharge planning and home care for end-stage COPD patients. Eur Respir J 2009;34:507-12. http://dx.doi.org/10.1183/09031936.00146308

28. Bunker J, Hermiz $\mathrm{O}, \mathrm{Zwar} \mathrm{N}$, et al. Feasibility and efficacy of COPD case finding by practice nurses. Aust Fam Physician 2009;38:826-30.

29. Fan VS, Gaziano JM, Lew R, et al. A comprehensive care management program to prevent chronic obstructive pulmonary disease hospitalizations: a randomized, controlled trial. Ann Intern Med 2012;156:673-83. http://dx.doi.org/10.7326/0003-4819-156-10-201205150-00003

30. Wilson PM , Kendall S, Brooks F. Nurses' responses to expert patients: the rhetoric and reality of self-management in long-term conditions: a grounded theory study. Int J Nurs Stud 2006;43:803-18. http://dx.doi.org/10.1016/j.jpnurstu.2005.10.011

31. Macdonald W, Rogers A, Blakeman T, Bower P. Practice nurses and the facilitation of self-management in primary care. J Adv Nurs 2008;62:191-9. http://dx.doi.org/10.1111/j.1365-2648.2007.04585.x

32. Walters JA, Courtney-Pratt $\mathrm{H}$, Cameron-Tucker $\mathrm{H}$, et al. Engaging general practice nurses in chronic disease self-management support in Australia: insights from a controlled trial in chronic obstructive pulmonary disease. Aust J Prim Health 2012;18:74-9. http://dx.doi.org/10.1071/PY10072

\section{Available online at http://w w w.thepcrj.org}

